\title{
Schistosoma mansoni Infection in Finchaa Sugar Estate: Public health Problem Assessment based on Clinical Records and Parasitological Surveys, Western Ethiopia
}

\author{
Mebrate Dufera $^{1 *}$, Beyene Petros ${ }^{2}$, Berhanu Erko $^{3}$, Nega Berhe ${ }^{4}$, Svein Gunnar Gundersen ${ }^{5}$ \\ ${ }^{1}$ Department of Biology, Wollega University, Post Box No: 395, Nekemte, Ethiopia \\ ${ }^{2}$ Department of Microbial, Cellular and Molecular Biology, Addis Ababa University, Post Box No: 395, \\ Addis Ababa, Ethiopia \\ ${ }^{3,4}$ Aklilu Lemma Institute of Pathobiology, Addis Ababa University, Post Box No: 395, Addis Ababa, Ethiopia \\ ${ }^{5}$ Sorlandet Hospital/Professor University of Agder, Oslo, Norway
}

\begin{tabular}{|c|c|}
\hline 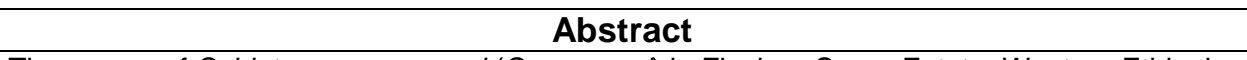 & Article Intorm \\
\hline \multirow{14}{*}{$\begin{array}{l}\text { The survey of Schistosoma mansoni (S. mansoni) in Finchaa Sugar Estate, Western Ethiopia, } \\
\text { was conducted to investigate the prevalence and health problems of schistosomiasis with } \\
\text { some of the risk factors. The examination was undertaken based on the analysis of } \\
\text { retrospective clinical data from the health center and a cross-sectional parasitological } \\
\text { examinations using Kato-thick smear slides in April-June } 2012 / 2013 \text {. Over the period } 2008 \text { to } \\
2013 \text { average prevalence among suspected patients at the health centre was } 30.9 \% \text {. } \\
\text { Examination of double kato-thick smear slides from a random sample of } 602 \text { individuals from } \\
\text { most schistosomiasis affected camp } 7 \text { revealed the prevalence of } 37.5 \% \text {. } S \text {. mansoni infection } \\
\text { is become a year-round public health problem in Finchaa, Sugar Estate possibly due to } \\
\text { permanent streams, water bodies and water contact behaviors and also reduced } \\
\text { effectiveness of current control measures. Among the } 7^{\text {th }} \text { camps, village A (camp } 7 \text { ) is the } \\
\text { most schistosomiasis affected area (37.5\%) followed by Kuyisa (25\%). This is attributed to the } \\
\text { presence of permanent stream (Fekerie stream) near camp } 7 \text {. The present finding shows that } \\
\text { the prevalence and intensity of schistosomiasis in the more affected camp } 7 \text { of Finchaa Sugar } \\
\text { Estate was significantly higher among males than in females and its prevalence and intensity } \\
\text { was found to be higher among study population within the age group of } 11-20 \text { years old. This } \\
\text { study indicates that schistosomiasis is a major health problem in Finchaa Sugar Estate with } \\
\text { moderate prevalence. The study results will provide an additional clinical and parasitological } \\
\text { data on the current status of } S \text {. mansoni in Finchaa Sugar Estate and could serve as a guide } \\
\text { in designing, developing and implementing intervention strategies to mitigate morbidity due to } \\
S \text {. mansoni especially in highly risk groups under the Ethiopian health service system. }\end{array}$} & matory. \\
\hline & Received : $30-0$ \\
\hline & ed \\
\hline & 14 \\
\hline & Is: \\
\hline & \\
\hline & \\
\hline & \\
\hline & is \\
\hline & \\
\hline & \\
\hline & \\
\hline & \\
\hline & \\
\hline
\end{tabular}

\section{INTRODUCTION}

Schistosomiasis is a parasitic disease caused by blood flukes of the genus Schistosoma. An estimated 700 million people are at risk of infection in 76 countries, considered endemic, as their agricultural work, domestic chores, and recreational activities expose them to infested water (Ross et al., 2007). After malaria, schistosomiasis is the second most devastating tropical disease in the world (Ross et al., 2007). The most important species that infect humans are $S$. japonicum, $S$. mansoni and $S$. haematobium. Adult schistosomes live in mammalian or human host and use freshwater snails as intermediate hosts. The schistosomes develop into adults in the blood vessels surrounding the urinary or intestinal tracts. Adults release eggs which can circulate and become lodged in the veins and other organs causing painful inflammation and chronic illness (Alam et al., 2009).
Geographic distribution of the disease depends on the distribution of intermediate snail host and the opportunity to infect humans and snails (Lima et al., 1987). Infection occurs throughout much of tropical and subtropical areas of the world. Transmission of $S$. mansoni relies on contamination of water by excrement, adequate environments for appropriate aquatic snail intermediate hosts, and skin exposure to contaminated water. Any contact with contaminated water such as bathing, washing clothes, collecting water for cooking, getting a drink, fishing, sailing, farming canal irrigated lands, and brick making could put one at risk of infection. As little as one exposure to cercariae-containing water per year is sufficient to maintain transmission (King and DangerfieldCha, 2008). Social, cultural, behavioral and economic factors interact with local environmental and ecological factors to produce extraordinary variation in the 
Mebrate Dufera et al.,

epidemiology of schistosomiasis with respect to prevalence and intensity of infection (Hibbs et al., 2011).

Infection is predominant in endemic countries in school age children, fishermen, farmers, irrigation workers and others using infested water for their domestic and/or recreational purposes. Epidemiologic studies in modern populations typically find a higher prevalence of schistosomiasis among males than females (AbdelWahab et al., 2000). This is likely the result of a gendered division of labor involving water contact.

In Ethiopia, both intestinal schistosomiasis caused by $S$. mansoni and urinary schistosomiasis caused by $S$. haematobium are pose considerable public health problem (Ali et al., 2006). In the country, S. mansoni is widely distributed and covering most of the places between 1300-2200m altitudes where as the distribution of $S$. haematobium is restricted to some lowlands below $800 \mathrm{~m}$ in Awash, Kurmuk (near the Sudan border) and Wabe Shebele areas (Erko et al., 1997a). In the Wester part of Ethiopia, most of the endemic places are located along Nile valley, in Finchaa Sugar Estate, Agallu-Meti and Dalati-Sirba areas (between Benishangul-Gumuz and Oromia) (Erko et al., 2003; Gundersen et al., 1998). In the country despite the fact that schistosomiasis is high in prevalence and associated morbidity especially in children (Berhe et al., 2009) and its control effort (Erko et al., 1997a) were not well studied and implemented.
Sci. Technol. Arts Res. J., April-June 2014, 3(2): 155-161

The Finchaa Sugar Estate in Western Ethiopia is such a large estate farm with an irrigation system, associated agro-industrial activities and high population influx. The area has significant occurrence of malaria and other parasitic diseases. Regarding S. mansoni Erko et al. (2003) reported that, there is a prevalence of $26 \%$ among the residents and $56 \%$ among the school children of the most schistosomiasis affected camp 7. Morbidity control, the current global strategy in the control of schistosomiasis, calls for research to assess the status of schistosomiasis with some of the risk factors. Therefore the present study was initiated in order to investigate the current extent/status of Schistosoma mansoni transmission and its public health importance in Finchaa Sugar Estate, Western Ethiopia.

\section{MATERIALS AND METHODS}

\section{Study Area, Study Subjects and Parasitological Examination}

Across-sectional study was undertaken from AprilJune 2012/2013 in about 602 study population, who participated in a $S$. mansoni related morbidity study in the selected village (camp 7) of Finchaa Sugar Estate located in Horro Guduru Wollega Zone of the Oromia Regional state, Wester Ethiopia. The area is about $350 \mathrm{~km}$ west of Addis Ababa and is situated between $9^{\circ} 30^{\prime} \mathrm{N}$ to $9^{\circ} 60^{\prime} \mathrm{N}$ latitudes and $37^{\circ} 10^{\prime}$ to $37^{\circ} 30^{\prime} \mathrm{E}$ longitudes and at an altitude of about 1,350-1600 m above sea level. The area is stretched in most part of the Finchaa River valley cultivating more than 10,500 hectares of irrigated land (Figure 1).

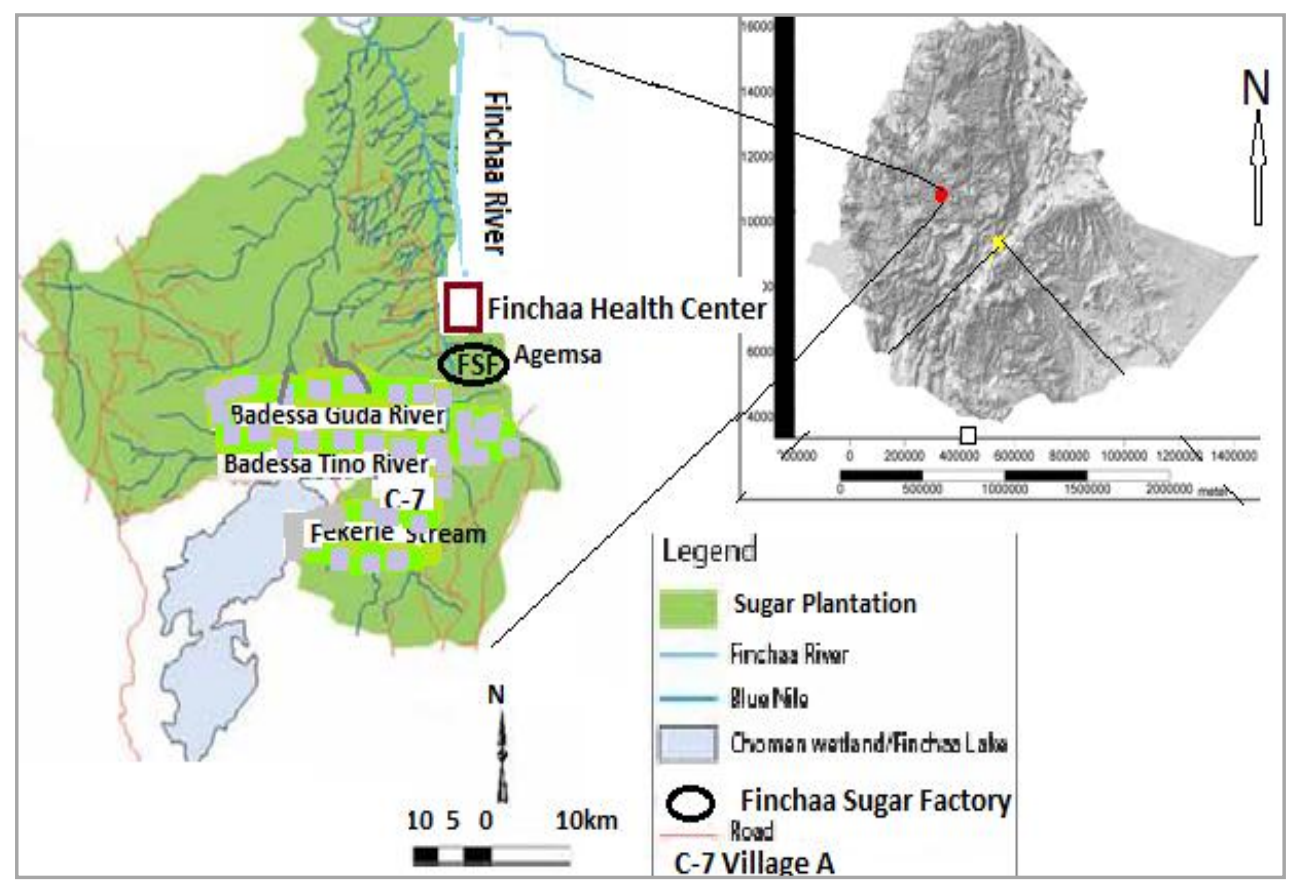

Figure1: Sketch-map of the study area -Finchaa Sugar Estate (Adapted from www.booker-tate.co.uk/media/4616/ethiopia\%20finchaa\%202010)

Table 1: The description of the study population in Finchaa (Camp 7) during April 2013 (N=602), Horro Guduru Wollega, Western Ethiopia.

\begin{tabular}{cccccccc}
\hline Village & \multirow{2}{*}{$\begin{array}{c}\text { Total household } \\
\text { No. (\%) }\end{array}$} & \multirow{2}{*}{$\begin{array}{c}\text { Sampled } \\
\text { household No. (\%) }\end{array}$} & $\begin{array}{c}\text { Total } \\
\text { population } \\
\text { No. (\%) }\end{array}$ & \multicolumn{2}{c}{ Sampled population No. (\%) } \\
\cline { 5 - 8 } & A (Camp 7) & 225 & 11 & 5000 & $322(53.5)$ & $280(46.5)$ & 602 \\
\hline
\end{tabular}


Using a computer software Open Epi, Version 2, SSCC, for a cross-sectional study, assuming OR=2.50 (Kelsey et al., 1996) about 602 individuals were taken at random from the census data of the study village. A day before the date of examination, field assistants visited all households selected for the study and invited all household members to provide stool specimens. Stool samples were processed using $41.7 \mathrm{mg}$ templates according to the modified Kato-Katz technique (Peters et al., 1980). For each study population, double Kato-Katz thick smears were prepared to optimize detection of $S$. mansoni infection. In order to express infection intensities as the number of eggs per gram of feces egg counts per slide were converted into eggs per gram of feces (EPG) by multiplying number of eggs on a slide by 24 . The intensity of infection for positive subjects were then expressed as geometric mean and categorized as light, moderate and heavy infections as per the WHO (2002) protocol. All smears were examined within two weeks of their collection by two experienced technicians at Finchaa health center. As a quality control measure, $10 \%$ of randomly selected smears were re-examined by a third experienced laboratory technician who is blinded of the previous results.

\section{Statistical Analysis}

Data were entered on a computer and validation were performed in Microsoft Excel 2007 spreadsheets, and transferred in to SPSS version 20.0 software for statistical analysis.

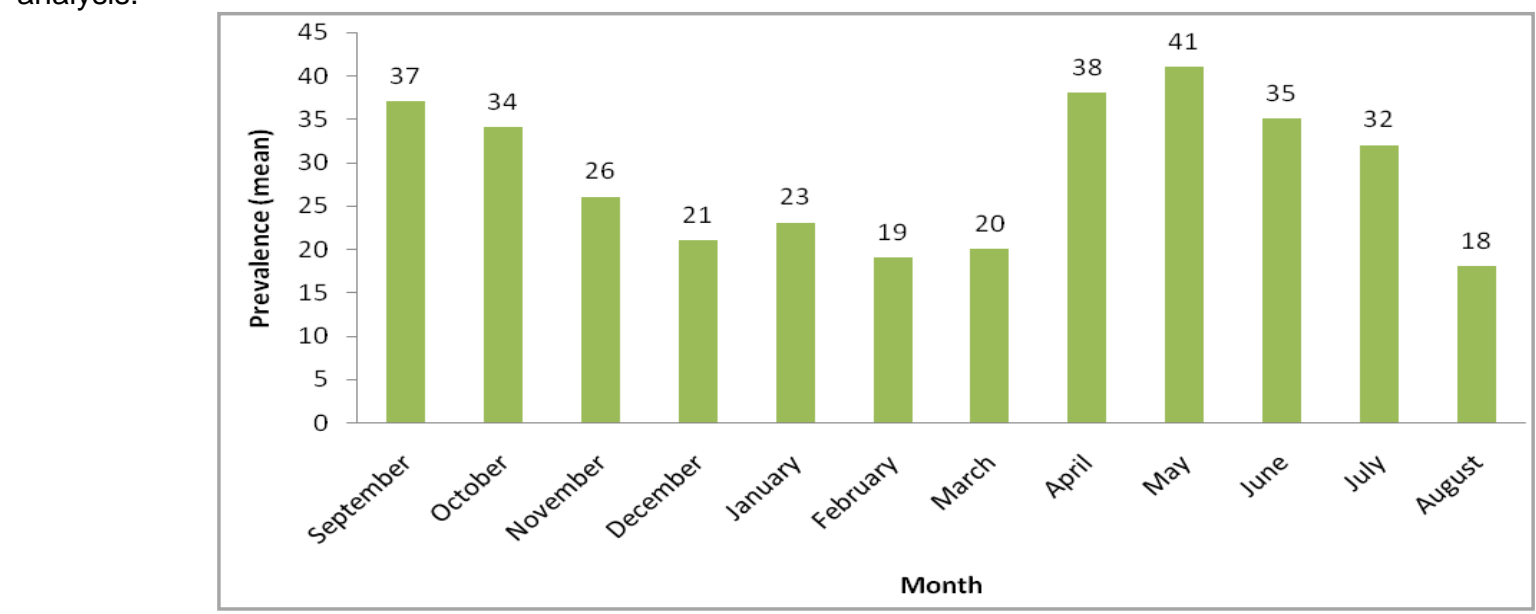

Figure 2: S. mansoni prevalence in Finchaa Health Center outpatients' from September to August in year 2008 to 2013.

Clinical records from 2008 to 2013 showed that there is a higher prevalence of schistosomiasis among males than females. This is attributable to more out door and

\section{Ethical Considerations}

Ethical clearance was obtained from Research and Development ethics review committee of Wollega University (Reference No: WU-RD/194/2013). The aims of the study were initially explained during a meeting of community leaders and heads of households. All diagnostic and treatment procedures were carried out after obtaining informed consent/assent from each subject or his/her guardians as the case may be. Free treatment was offered to all study population with schistosomiasis and/or other helminth infections under the supervision of Finchaa health center physician based on the national protocol.

\section{RESULTS}

\section{Demographic Data}

From the total of 602 study population (from Camp 7) $322(53.5 \%)$ were males and $280(46.5 \%)$ were females. The mean age of the study population was $21.47 \pm 13.32$.

\section{Clinical Records}

Clinical records of monthly mean prevalence from 2008-2013 showed that there is a higher prevalence of schistosomiasis after heavy rainy seasons (September and October) and during small rainy seasons (April, May and June). This is due to the favorable environmental conditions created by the rainy seasons for snail vector (Biomphlaria piffeferi) to be more reproduced.

water related activities among men than women (a gendered division of labor).

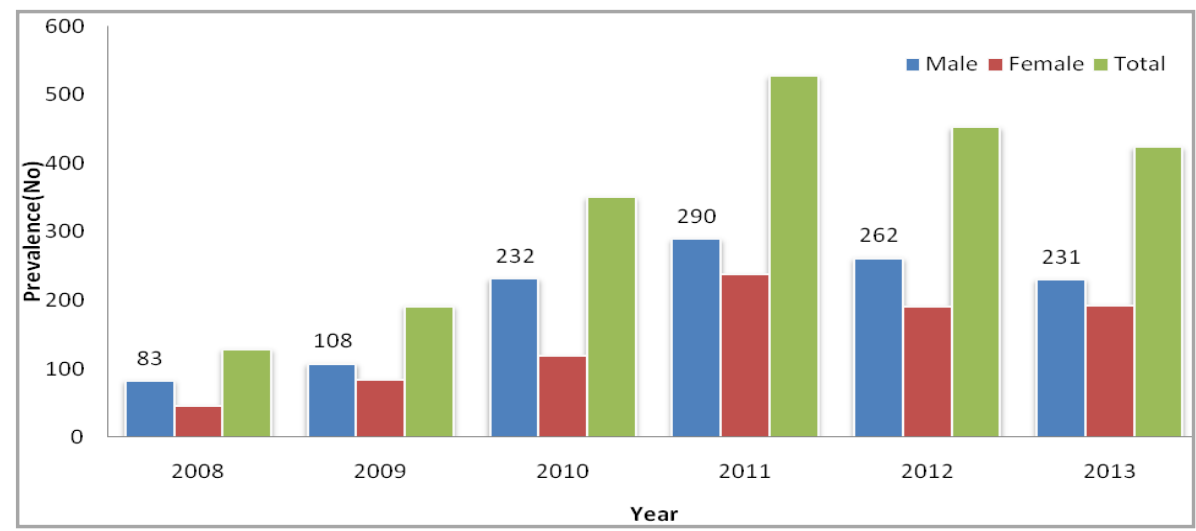

Figure 3: Sex specific prevalence of S. mansoni in Finchaa Health Center outpatients' from year 2008 to 2013. 
Mebrate Dufera et al.,

Sci. Technol. Arts Res. J., April-June 2014, 3(2): 155-161

Clinical records of $S$. mansoni in relation to other intestinal helminths from year 2008 to 2013 showed that S. mansoni infection is the first and most prevalent among other intestinal helminths. This is thought to be due to favorable environmental conditions created by the irrigation activities.

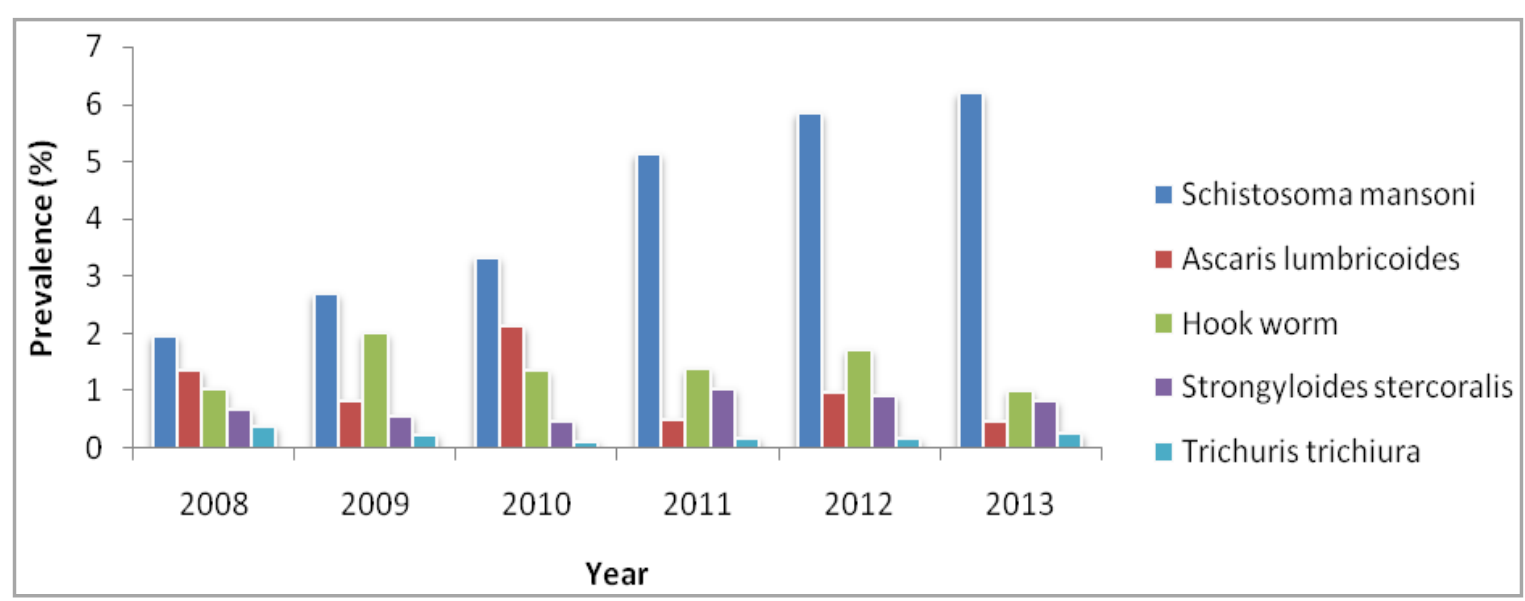

Figure 4: S.mansoni prevalence in relation to other intestinal helminths in Finchaa Health Center outpatients' from year 2008 to 2013

\section{Parasitological Results}

Among the 602 study populations examined from Camp7, $226(37.5 \%)$ were positive for S. mansoni with geometric mean intensity, of $239.59 \pm 172.94$ eggs per gram of stool and a maximum intensity of 912 EPG among male and 576 in female.
Among the $7^{\text {th }}$ camps, village A (camp 7) is the most schistosomiasis affected area (37.5\%) followed by Kuyisa $(25 \%)$. This is attributed to the presence of permanent stream (Fekerie stream) near camp 7 in addition to the numerous irrigation canals throughout the year.

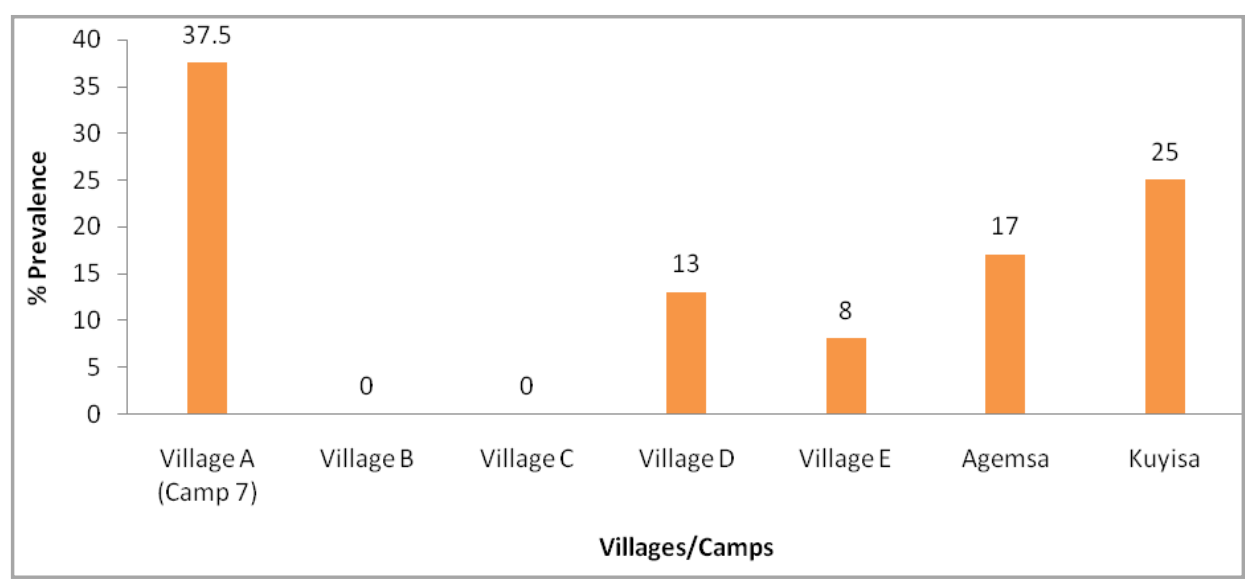

Figure 5: S.mansoni distribution and prevalence among villages of Finchaa Sugar Estate, April 2013

The highest infection of helminth cases was due to $S$. mansoni $(37.5 \%)$ followed by hookworm infection $(21 \%)$ and S. stercoralis (17\%).Other Intestinal helminths which were not specifically shown here because of their extremely low prevalences includes: Taenia saginata, $H$. nana, $H$. diminita and Enterobius vermicularis.

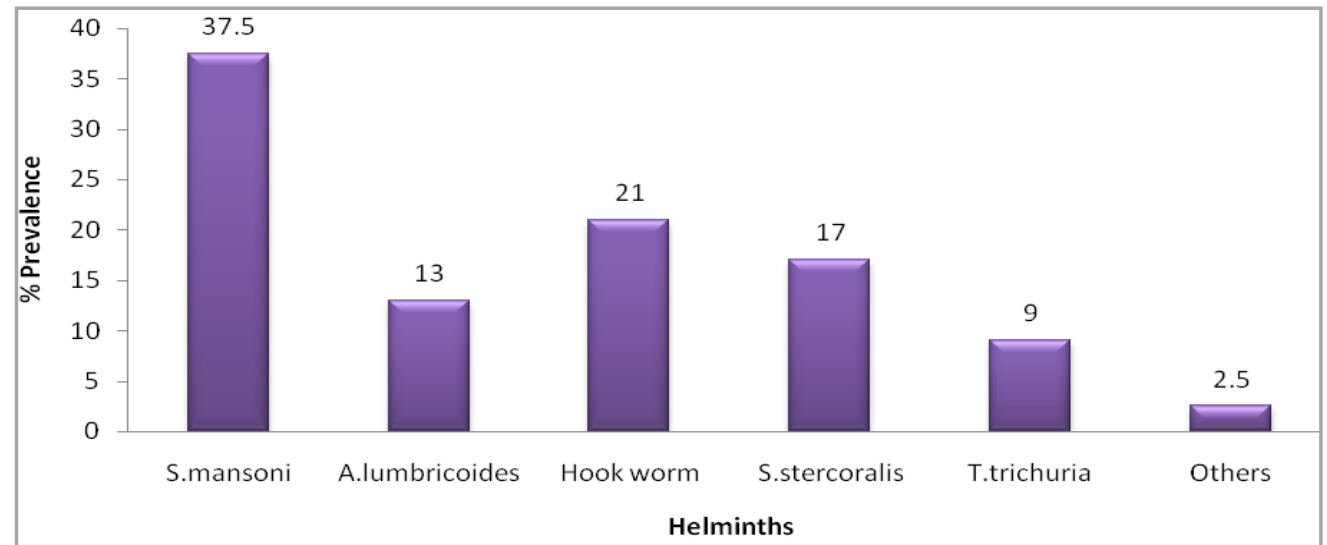

Figure 6: S.mansoni prevalence in relation to other intestinal helminths among study population in Camp 7, Finchaa Sugar Estate, April 2013 ( $n=226)$. 
Of the 226 S.mansoni positive individuals, the prevalence was 151 (66.81\%) among male study

population which is higher than the prevalence in females 75(33.19\%).

Table 2: Sex specific prevalence and intensity of S.mansoni among study population in Camp 7, Finchaa Sugar Estate, April $2013(n=226)$.

\begin{tabular}{ccc}
\hline Sex Category & Prevalence n, (\%) & Mean Intensity EPG \pm SD \\
\hline Male & $151(66.81 \%)$ & $0.99 \pm 0.757$ \\
Female & $75(33.19 \%)$ & $0.80 \pm 0.658$ \\
\hline
\end{tabular}

The study population were classified in to five age groups (5-10, 11-20, 21-30, 31-40 and >40); based on this age category, the prevalence of $S$. mansoni was found to

be higher among children within the age group of $11-20$ (39.4\%) years old (Table 3$)$.

Table 3: Age specific S. mansoni infection and intensity in Finchaa from April 2013 among study population in Camp 7, Finchaa Sugar Estate, $(\mathrm{n}=226)$.

\begin{tabular}{ccc}
\hline Age category & Prevalence $\mathbf{n ,}(\%)$ & Mean intensity EPG $\mathbf{\pm}$ SD \\
\hline $5-10$ & $84(37.16 \%)$ & $180.62 \pm 161.12$ \\
$11-20$ & $89(39.38 \%)$ & $251.06 \pm 159.15$ \\
$21-30$ & $33(14.60 \%)$ & $301.09 \pm 173.18$ \\
$31-40$ & $11(4.86 \%)$ & $272.73 \pm 215.27$ \\
$>40$ & $9(3.98 \%)$ & $410.67 \pm 165.16$ \\
\hline
\end{tabular}

Based on WHO intensity category the intensity (EPG) of $S$. mansoni among different age groups was found to

be higher among children within the age group of 11-20 years old (Fig.7).

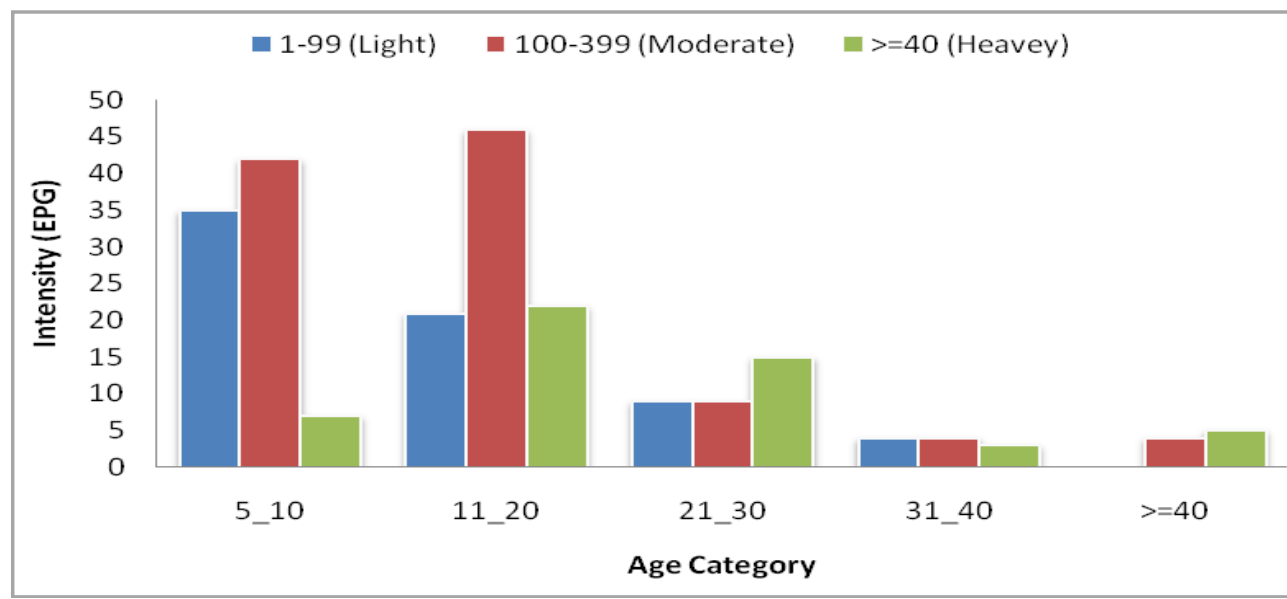

Figure 7: Age specific prevalence and intensity of S. mansoni in Camp 7, Finchaa Sugar Estate, April 2013, $(n=226)$.

\section{DISCUSSION}

The study area falls within an area of S.mansoni endemicity in Ethiopia. In addition to the favorable climatic factors, there exists extensive irrigation farming which could create favorable conditions for a year-round schistosomiasis transmission. The presences of temporary and permanent streams in addition to the numerous irrigation canals are additional factors that may favor schistosomiasis transmission throughout the year. A clinical record showed that schistosomiasis has been increased from year to year (Fig.4). This is most likely due to population migration associated with irrigation development (Erko et al., 1997a). The main aim of the study was to assess the current status of schistosomiasis in morst schistosomiasis affected area camp 7.

In this study, the prevalence of $S$. mansoni among the community in the most schistosomiasis affected camp of Finchaa Sugar Estate (Camp 7) was 37.5\% with geometric mean intensity, of $208.60 \pm 163.44$ eggs per gram of stool. The disease has increased from $26 \%$ among the residents (Erko et al., 2003) to $37.5 \%$ as a result of population migration from time to time associated with irrigation development and expansion which is consistent with previous studies by Erko et al. (1997a).

In relation to other intestinal helminths among study population the highest infection of helminth cases was due to $S$. mansoni (37.5\%) followed by hookworm infection (21\%) and $S$. stercoralis (17\%). This highest infection due to schistosomiasis might be the result of irrigation developments. It is well known that a strong association exists between water resource development projects, especially irrigation, and the transmission of schistosomiasis (Dejenie and Petros, 2009).

The present finding shows that the prevalence and intensity of schistosomiasis in the most schistosomiasis affected camp 7 of Finchaa Sugar Estate was significantly higher among males $(66.81 \%$ and $0.99 \pm 0.76 \mathrm{EPG})$ than 
in female (33.19.\% and 0.80 \pm 0.66 EPG) (Table 2). The result is almost in agreement with previous studies conducted by Erko et al. (2003) which reported that the prevalence and mean intensity of the disease was $63.00 \%$ and 125 EPG among male and 44\% and 92 EPG among females. Similarly, studies conducted in Wondo Genet (Erko et al., 2002b) and Adwa (Legesse, 2008) also indicates similar results. The main reason accounted for this high infection of male was attributable to more out door and water related activities among men than women (Tadesse, 2005; Legesse, 2008). In addition, a study on re-infection patterns among Finchaa valley elementary school children also indicated that, male children are more engaged in bathing and playing in water than the females (Erko et al., 1997b).

WHO (2002) classifies the prevalence of schistosomiasis into three categories i.e., a prevalence rate $>50 \%$ as category I (high prevalence), $10 \%-50 \%$ as category II (moderate prevalence) and a prevalence of lower than $10 \%$ as category III (low prevalence). In this context, in the present study since S.mansoni prevalence was $(37.5 \%)$ and less than $50 \%$ it is categorized under category II (moderate prevalence).

Regarding age groups the prevalence and intensity of S. mansoni infection was found to be higher among study population within the age group of $5-10$ and $11-20$ years old (5-20) (Table 3 and Fig.5).This is in agreement with previous studies conducted by Gunderson et al., (1990). Chronic infection negatively affects all aspects of children's health, nutrition, cognitive development and learning. The main reason accounted for this high infection rate among age 5-20 years old was attributable to more water related activities than other or older age groups.

\section{CONCLUSIONS}

The present clinical and parasitological survey is a study of public health problem assessment of Schistosoma mansoni infection. Based on information from clinical records and the parasitological survey data, the following conclusions and recommendations may be drawn about $S$. mansoni infection.

S. mansoni is among the major causes of morbidity and become a serious public health problem in most schistosomiasis affected camp of Finchaa Sugar Estate (Camp 7). Its prevalence in relation to other intestinal helminths among study population is $37.5 \%$ and shows the dominance infection. There is a higher prevalence of schistosomiasis after heavy rainy seasons (September and October) and during small rainy seasons (April, May and June). The study shows that there is a higher prevalence of schistosomiasis among males than females. The prevalence and intensity of $S$. mansoni among different age groups is found higher among children within the age group of 11-20 years old. Hence it has a serious health problem on this age groups and chronic infection negatively affects all aspects of children's health, nutrition, cognitive development and learning. The degree of water contact extensively for bathing, swimming, washing and domestic purpose is become the most important risk factor for infection of intestinal schistosomiasis. This survey can be used for the design and implementation of some intervention strategies to mitigate morbidity due to schistosomiasis.
Schistosomiasis survey in the community should be done more often accompanied with targeted chemotherapy for positive cases. Public health education, community participation and socioeconomic developments are necessary for reducing the risk of $S$. mansoni infection. In addition to the applications of chemotherapy against the parasite, Endod application against the snail vector should be used side by side.

\section{ACKNOWLEDGEMENTS}

I would like to express my deepest gratitude to my home institution Wollega University for the financial support. Secondly, I would like to thank Finchaa Health Centre medical doctors: Dr Sori Raje and Dr.Tolossa Gishile, technical staffs and Camp 7 Clinicians for their unreserved support. Also my special thanks go to Finchaa Sugar Factory administrative staffs in general and Finchaa Health Centre administrative staffs in particular for their essential logistic support during site survey.

\section{REFERENCES}

Abdel-Wahab, M., Esmat, G., Ramzy, I., Narooz, S., Medhat, E., Ibrahim, M., El-Boraey, Y. and Strickland, G. (2000). The epidemiology of schistosomiasis in Egypt: Fayoum Governorate.American Journal of Tropical Medicine and Hygiene 62: 55-64.

Alam, K., Maheshwari, V., Jain, A., Siddiqui, F. A., Haq, M. E., Prasad S. and Hasan, A. S. (2009). Schistosomiasis: a case series, with review of literature. Internet Journal of Infectious Diseases 7(1).

Ali, A., Erko, B., Wolde-Michael, T. and Kloos, H. (2006). Schistosomiasis. PP. 660-673. In: The Epidemiology and Ecology of Health and Disease in Ethiopia. eds. B. Yemane, H. Damen and H. Kloos. Shama Books, Addis Ababa, Ethiopia.

Berhe, N., Myrvang, B. and Gundersen, S.G. (2009). Gastrointestinal symptoms associated with intense Schistosoma mansoni infection affect class-attentiveness of schoolchildren in Ethiopia. Acta Tropica 110(1): 52-56.

Dejenie, T. and Petros, B. (2009).Irrigation Practices and Intestinal Helminth Infections in Southern and Central Zones of Tigray. Ethiopian Journal of Health Development 23(1): 48-56.

Erko, B., Gemetchu, T., Medhin, G. and Birrie, H. (1997b). Re-infection of school children with Schistosoma mansoni in Finchaa valley, Western Ethiopia. Ethiopian Journal of Health Development 11(3): 266-273.

Erko, B., Medhin, G., Berhe, N., Abebe, F., Gebre-Michael, T. and Gundersen, S.G. (2002b). Epidemiological studies on intestinal schistosomiasis south Ethiopia. Ethiopian Medical Journal 40(1): 29-39.

Erko, B., Medihin, G., Balcha, F. and Raje, S. (2003). Evaluation of pilot control trial of intestinal schistosomiasis in Finchaa Sugar Estate, Ethiopia. Ethiopian Medical Journal 41:141-150.

Erko, B., Tedla, S. and Wolde-Yohannes, L. (1997a). Current status of schistosomiasis in Ethiopia. In: Aklilu Lemma International Memorial Symposium Proceedings. P 48-59. Sep. 18-19. Faculty of Science, Addis Ababa University, Addis Ababa, Ethiopia.

Gundersen, S.G., Birrie, H., Torvik, H.P., Medihin, G. and Mengesha, H. (1998). Delayed re-infection of Schistosoma mansoni in Blue Nile valley of Western Ethiopia 10 years after mass chemotherapy. Acta Tropica 70(1): 35-42. 
Gundersen, S.G., Birrie,H., Torvik, H.P. and Scherbaum, H. (1990). Control of Schistosoma mansoni in the Blue Nile Valley of Wester Ethiopia by mass chemotherapy \& focal snail control: a primary health care experience. Royal Society of Tropical Medicine and Hygiene 84:819-825.

Hibbs, A.C., Secor, W.E., Van-Gerven, D. and Armelagos, G. (2011). Irrigation and infection: The immune-epidemiology of schistosomiasis in ancient Nubia. American Journal of Physical Anthropology 145: 290-298.

Kelsey (1996). Methods in Observational Epidemiology $2^{\text {nd }}$ Ed. Table 12-15 Fleiss, Statistical Methods for Rates and Proportions, formulas 3.18 \& 3.19. New York: Oxford University Press.

King, C.H. and Dangerfield-Cha, M. (2008). The unacknowledged impact of chronic schistosomiasis .Chronic Illness 4: 65-79.

Legesse, L.W. (2008). Current status of Schistosoma mansoni and soil-transmitted helminthiasis in primary school children of Adwa town, Northern Ethiopia. MSc Thesis. ALIPB. Addis Ababa University. Addis Ababa, Ethiopia.
Lima, E.C., Magalhaes, H.A., Rocha, R.S., Antune, S.C and Katz, N. (1987). Water-contact patterns and socioeconomic variables in the epidemiology of $S$. mansoni in an endemic area in Brazil. Bulletin of the World Health Organization 65: 57-66.

Peters, P.A., El Alamy, M., Warren, K.S.and Mahmoud, A.A.(1980). Quick Kato smear for field quantification of Schistosoma mansoni eggs. American Journal of Tropical Medicine and Hygiene 29: 217-219.

Ross, A., Vickers, D., Olds, G.R., Shsh, S.M. and McManus, D.P. (2007). Katamaya syndrome. Lancet Infectious Diseases 7: 218-224.

Tadessa, G. (2005). The prevalence of intestinal helminthic infections and associated risk factors among school children in Babile town, eastern Ethiopia. Ethiopian Journal of Health Development 19(2): 140-147.

WHO (2002). Prevention and control of schistosomiasis and soil transmitted helminthiasis. Technical report series 912 . Geneva, Switzerland. 63pp.

www.booker-tate.co.uk/media/4616/ethiopia\%20finchaa\%202 010 